\title{
The power of voting and corruption cycles
}

\author{
E. Accinelli , Filipe Martins , Alberto A. Pinto , Atefeh Afsar \& Bruno M. P. M. \\ Oliveira
}

To cite this article: E. Accinelli , Filipe Martins, Alberto A. Pinto, Atefeh Afsar \& Bruno M. P. M. Oliveira (2020): The power of voting and corruption cycles, The Journal of Mathematical Sociology, DOI: $10.1080 / 0022250 X .2020 .1818077$

To link to this article: https://doi.org/10.1080/0022250X.2020.1818077

曲 Published online: 16 Sep 2020.

Submit your article to this journal

Q View related articles $\longleftarrow$

View Crossmark data ¿ 


\title{
The power of voting and corruption cycles
}

\author{
E. Accinelli ${ }^{a}$, Filipe Martins ${ }^{b}$, Alberto A. Pinto ${ }^{b}$, Atefeh Afsar ${ }^{b}$, \\ and Bruno M. P. M. Oliveira ${ }^{c}$ \\ aFacultad de Economía de la Universidad Autónoma de San Luis Potosí, San Luis Potosí, S. L. P., Mexico; \\ bLIAAD-INESC TEC, Department of Mathematics, University of Porto, Porto, Portugal; ' LIAAD-INESC TEC, \\ Faculdade de Ciências da Nutrição e Alimentação da Universidade do Porto, Porto, Portugal
}

\begin{abstract}
We introduce an evolutionary dynamical model for corruption in a democratic state describing the interactions between citizens, government and officials, where the voting power of the citizens is the main mechanism to control corruption. Three main scenarios for the evolution of corruption emerge depending on the efficiency of the institutions and the social, political, and economic characteristics of the State. Efficient institutions can create a corruption intolerant self-reinforcing mechanism. The lack of political choices, weaknesses of institutions and vote buying can create a self-reinforcing mechanism of corruption. The ambition of the rulers can induce high levels of corruption that can be fought by the voting power of the citizens creating corruption cycles.
\end{abstract}

\section{ARTICLE HISTORY}

Received 4 June 2020

Revised 22 August 2020

Accepted 29 August 2020

\section{KEYWORDS}

Corruption; democracy; evolutionary game theory; replicator dynamics; heteroclinic cycles; social traps

\section{Introduction}

Corruption is one of the most relevant issues in political science and related fields of study in the social sciences. A multitude of economical and sociological effects of corruption have been identified. Moreover, a great deal of empirical and theoretical studies have been produced, regarding the endemic characteristics of corruption and its outreaches. Corruption has a large impact on economies as a whole (see for instance the European Union (EU) (2014) report on the effects of corruption). ${ }^{1}$ Corruption degrades the welfare of the individuals and the political, social and economical structure of the society (see for instance Gupta, Davoodi, and Alonso-Terme (2002)). Corruption can affect the trust, faith, and legitimacy of democratic regimes (see, for example, Boswell and Rose-Ackerman (1996); Seligson (2002); Warren (2004)). In several countries, cycles of corruption have been observed that may be associated with electoral cycles and alternation of political parties in power (see, for example, Sidorkin and Vorobyev (2015) and Soto and Cortez (2015)).

CONTACT E. Accinelli elvio.accinelli@eco.uaslp.mx Facultad de Economía de la Universidad Autónoma de San Luis Potosí. San Luis Potosí, México. Av Pintores S/N, colonia Burócratas del Estado. CP 78213. San Luis Potosí, S. L. P., México

${ }^{1}$ The European Union published its first ever anti-corruption report in February 2014, where it concluded that bribery, embezzlement, financial and tax fraud, money laundering, cronyism, etc., "(...) cost the EU economy 120 billion euros per year, just a little less than the annual budget of the European Union". 
In broad terms corruption can be defined as the misuse of public power for private benefit (as defined by the NGO Transparency International (TI)). Jain (2001) suggests the following types of corruption: grand corruption, involving political elites; bureaucratic corrupt practices involving appointed bureaucrats or officials that deal more directly with citizens and corrupt acts occurring when they meet the public; legislative corruption, i.e., when voting behavior and policy making of the legislator are influenced by private interests, and lobbying. Following Jain (2001), we propose an evolutionary game theoretic dynamical model to study the evolution of corruption in a democratic state, where the ruler elite, the officials and the citizens are the main players. The ruler elite is represented by the elected government. The government can appoint and support corrupt or honest officials. The officials or bureaucrats, who represent the state institutions, provide services such as building permits, licenses to the exploration of natural resources, control of compliance with laws, control of tax payments, and various other kinds of management of the state. Corrupt governments may be accomplice of corrupt officials, for instance, by not applying adequate fines. Oppositely, honest governments, in order to be efficient, will necessarily need an appropriate judiciary system to fight corruption. When the government is corrupt, citizens may become compliant with it in their daily lives because fighting corruption can be too costly. When corruption persists, citizens may have a gain due to practices that may be classified as clientelism, cronyism or vote buying. ${ }^{2}$ In a democratic state with several political parties, the compliant citizens, aware of the longrun welfare undermining due to high corruption levels, can use their voting power to overturn the corrupt government or to force the replacement of the corrupt government members. Hence, the actions of the government toward corruption depend on citizens' actions and vice-versa, quoting Victor Hugo (1864): "Il y a solidarité appréciable et honte partagée entre le gouvernement qui fait le mal et le peuple qui le laisse faire".

Evolutionary game theory is a powerful tool to predict the time dynamics of the agents' strategic decisions involved in social conflicts, like corruption phenomena (see Accinelli and Carrera (2012); Accinelli et al. (2017); Bicchieri and Duffy (1997)). Here, comparing with Accinelli et al. (2017), we include the citizens as agents of the model. This allows us to study: (i) the time evolution of the citizens' strategies; (ii) their (time) dependence/influence on the evolution of the strategies of the government and officials; and (iii) the time dependence of the influence and strength of citizens' voting power in deterring corruption. The state of the system is the triple $(g, o, c)$, where: (i) $g$ is the proportion of the corrupt acts by the government; (ii) $o$ is the proportion of corrupt officials; and (iii) $c$ is the proportion of compliant citizens. The

\footnotetext{
${ }^{2} \mathrm{~A}$ paradigmatic episode of vote buying occurred in XVIII century England in the "Spendthrift election" in Northamptonshire Grego (1886), when three earls spent over 100, 000 pounds each to win a seat.
} 
agents change their strategies along time with the goal of improving their respective payoffs, taking into account the strategies of the other agents. Firstly, we focus our attention on the no-corruption scenario $(0,0,0)$. The stability of the equilibria without corruption is driven by the following main factors: the government voting valuation for non-compliant citizens (those who do not perceive or do not care about government corruption) is greater than what can be obtained with corrupt actions (those that could be supported by these citizens) that the government could try to implement or practice; and for the benefits obtained from the penalties imposed on corrupt officials by the non-corrupt government that turn out to be higher than the benefits obtained from the corrupt practices of officials. Secondly, we focus our attention on the full corruption scenario $(1,1,1)$. The stability of the full corruption equilibrium is driven by the following main factors: the gains with the corrupt actions of the government and efficient vote-buying practices overcome the benefits from stopping corruption; the gains of officials with corrupt acts are large enough to buy the complicity of the corrupt government because of low punishments; the judiciary system does not work well; and social beliefs of citizens in the political system to fight corruption are low. Thirdly, we focus our attention on the corruption cycles scenario. This scenario is driven by the existence of a saddle-mixed equilibrium with a negative eigenvalue and a pair of complex eigenvalues with positive real part. The boundary of its twodimensional unstable manifold is a stable heteroclinic cycle. ${ }^{3}$ Hence trajectories spiral around the mixed Nash equilibrium toward the stable heteroclinic cycle implicating the cycles of corruption. The existence of corruption cycles is driven by the following main factors: when levels of corruption are low, the gains with corrupt government actions are higher than the effects of voting of the government from the non-compliant citizens that still do not perceive the government corruption and so do not oppose corruption; as a result, the profits of the officials with the corrupt acts are large enough to buy the complicity of the corrupt government; consequently, the level of corruption increases, and citizens in general, at least in principle, have to adapt and comply with corruption in their daily life since fighting corruption carries a high cost; however, as this occurs, perception of corruption increases in compliant citizens that do not tolerate high levels of corruption and so fight corruption by using the power of their vote, and so the corrupt government sees this as a threat to its goals of staying in power and finds it opportune to become less corrupt to increase its chances of reelection (or the government could be replaced by a less corrupt government through elections), the government decreases its corrupt acts and therefore increases sanctions imposed on corrupt officials, leading again to low levels of officials' corruption. Now

\footnotetext{
${ }^{3} \mathrm{An}$ heteroclinic cycle is a path in the phase/state space of a dynamical system connecting different equilibrium points and eventually ending in the first equilibrium, hence making a cycle. As is the case with fixed points and periodic orbits, such cycles may be stable or unstable.
} 
these behaviors are repeated creating corruption cycles. In many cases, it is observed that even when the ruling elite changes, the cycle repeats (see Soto and Cortez (2015)).

This paper is organized as follows. In section 2 we introduce the threepopulation game and we successively describe the payoffs of the players of the game. In section 3 we introduce the evolutionary dynamical model for corruption in a democratic state and we discuss the dynamical equilibria of the system. In section 5 we show the existence of a stable heteroclinic cycle of corruption. In section 4 we analyze a bi-stable situation where low and high levels of corruption are stable. The concluding remarks are presented in section 6.

\section{The model}

We consider a three-population, two-strategy normal-form game where the populations are: the citizens, the government, i.e., the political elite (elected directly by universal suffrage of citizens), and the officials appointed and hired directly by the government to carry out administrative or bureaucratic tasks of the State. The government may be regarded as a first-level elite. The officials may be regarded as a second-level elite. For simplicity we assume that the group of officials is small while compared to the citizens group. In other words, since the group of officials is small, it has a negligible influence in elections since they are heavily outnumbered by citizens. At the end of each electoral period, citizens reelect the current government or not. The officials must choose between to accomplish their task in an honest way or to require citizens an illegal payment for the purpose of performing some task. It may be for the fulfillment of some service or the payment of some bribe after some infraction by a citizen. It is up to the ruler elite or government to choose between punishing or being an accomplice of corrupt officials. In the first case we say that the government acts in an honest or non-corrupt way and in the second one we say that the government is acting in a corrupt way. Lastly, citizens may act compliantly or non-compliantly with corruption. This does not mean that the citizen is corrupt or not, but only tells us about their reactions toward corruption. In fact, a typical citizen probably does not like corruption, but can act in a manner compatible with corruption because it increases its utility.

Summarizing, we have a game with three populations: citizens, government, and officials, where each one must choose between two pure strategies. This game is symbolized by the formal expression: $\Gamma=\{\mathbf{P}, \mathbf{S}, \mathbf{U}\}$, where

- $\mathbf{P}=\{\mathcal{G}, \mathcal{O}, \mathcal{C}\}$ represents the players or populations of the game where $\mathcal{G}$ denotes the government, $\mathcal{O}$ denotes the officials and $\mathcal{C}$ denotes the citizens.

- $\mathbf{S}=S_{\mathcal{G}} \times S_{\mathcal{O}} \times S_{\mathcal{C}}$ is the strategy space of the game where $S_{\mathcal{G}}=\{G, \bar{G}\}$, $S_{\mathcal{O}}=\{O, \bar{O}\}$ and $S_{\mathcal{C}}=\{C, \bar{C}\}$ represent the sets of pure strategies for each 
player, namely, to be corrupt or non-corrupt for the government and the officials and compliance with corruption or not for the citizens. Throughout this work an over-line will denote non-corrupt or non-compliant behavior.

- U represents the utilities or pay-offs obtained by each player depending on his/her own strategy and on the strategies followed by the other players.

Furthermore, as usual, a mixed strategy for each player is a probability distribution over his/her pure strategies. This mixed strategy can also be seen as a distribution of a population over its pure strategies. We will denote by $(g, 1-g)$ the distribution of corrupt and non-corrupt acts of the government, by $(o, 1-o)$ a distribution of the officials over the two strategies described above, i.e. corrupt or non-corrupt officials, and by $(c, 1-c)$ we represent a distribution of the citizen's population, i.e. compliant or non-compliant behavior.

In the next three subsections we shall describe the pay-offs of the game that will reflect several types of corruption and citizens' reactions to corruption and several instances it may take in a society.

\subsection{The citizens}

We consider that citizens have two possible behaviors or strategies: the one of acting compliantly with a corrupt government, or non-compliantly toward governmental corruption. This may be interpreted, in the extreme case of vote buying, that citizens are willing to receive some payment from a corrupt government. In less extreme cases, it may be regarded as simply compliance toward corruption - even if displeasing, because of lack of alternatives, or because corruption prevails so that accepting it can increase their utility. In other words, the presence of government corruption might locally or in the short-run increase citizens' utility and they are thus forced to change their behavior due to corruption of the system. Of course, no citizen likes corruption explicitly but for some reason he/she might be compelled to have some degree of compliance toward a corrupt government. Cases of clientelism and cronyism may be thought of to interpret this situation. We may also interpret social inaction to government corruption as silent compliance as being noncompliant may bear (social) costs and efforts from citizens. In our model, when there is no corruption (at both government and official level) citizens will be non-compliant since there is no corruption, deriving some degree of satisfaction. When the government is corrupt, citizens' beliefs against corruption may lead them to change their behavior and become compliant or not according to the partial benefits they may get from government corruption. Furthermore, even when the government is non-corrupt citizens may contact officials which may be corrupt and this might lead them to change their strategy according to the utility or dis-utility he/she gets from such contact with corrupt officials. For instance they might be compliant toward the 
government and demand that they punish corrupt officials and diminish corruption. The question of long-term evolution of government corruption will then depend on how this change of utility of the citizens might work or not as a positive or negative feedback in the evolution of corruption, whose effect is related to citizens voting power, as we shall see further along.

The profits corresponding to each type of citizen are represented in Table 1 and the parameters are as follows:

- -1 is the dis-utility corresponding to the payment that citizens must make when they encounter a corrupt official. Without loss of generality, we assume it as the monetary unit.

- $U_{O}$ is the extra dis-utility or dissatisfaction that non-compliant citizens assign when they encounter corrupt officials when compared to the compliant citizens. This value represents an extra cost that the corrupt officials impose on citizens that do not accept to practice non-legal acts.

- $U_{C}$ is a utility transferred from the government to the compliant citizens due to government practices in favor of corruption like vote buying, favoritism, clientelism, cronyism, misleading propaganda, among other costs. It is not due to a socially induced welfare gain but a utility gain due to the corrupt behavior of the government.

- $U_{G}$ is an extra utility obtained by the non-compliant citizens when the judiciary system still works well, or due to moral and/or social beliefs of noncompliant citizens against corruption.

- $U_{\bar{G}}$ is the utility of the citizens by not having to be compliant when the institutions and the judiciary system work well and protect the citizens.

At this point, for simplification of notation and presentation it is worth making the following comment regarding a usual type of simplification for the payoff matrices.

Remark 1. The fact that a compliant citizen assigns payoff 0 and a noncompliant citizen assigns payoff $U_{\bar{G}}$ when government and officials are noncorrupt is not a restriction for the model and subsequent analysis. More precisely, instead of assigning 0 to a compliant citizen and $U_{\bar{G}}$ to a non-compliant citizen when facing a non-corrupt government, we could have assigned the payoffs $U_{C, \bar{G}}$ and $U_{\bar{C}, \bar{G}}$, respectively. Indeed, the relevant quantity for the future analysis is the difference

$$
U_{\bar{G}} \equiv \Delta U_{\bar{G}}=U_{\bar{C}, \bar{G}}-U_{C, \bar{G}} .
$$

A similar analysis holds for several other quantities. In particular, this analysis can help to interpret why some quantities can be positive or negative, because the

Table 1. The pay-off table of the citizens in the three-population game.

\begin{tabular}{lllll}
\hline & $G, O$ & $G, \bar{O}$ & $\bar{G}, O$ & $\bar{G}, \bar{O}$ \\
$C$ & $U_{C}-1$ & $U_{C}$ & -1 & 0 \\
$\bar{C}$ & $U_{G}-\left(1+U_{0}\right)$ & $U_{G}$ & $U_{\bar{G}}-\left(1+U_{0}\right)$ & $U_{\bar{G}}$ \\
\hline
\end{tabular}


sign can result from this implicit comparison. This simplification is used when the economic and social interpretations are clear.

The parameter $U_{C}$ corresponds to a simplified version of possible royalties granted by corrupt governments to possible electors. In the case of entrepreneurs, it may correspond to public concessions or, in the case of poor families of developing countries, to certain consumption bundles. In this way, $U_{C}$ represents the effect of clientelism, which is usually defined as the exchange of goods and services for political support, either explicitly or implicitly through certain asymmetric relationships between different social and political groups (see Stokes 2005, 2009). In this way it may be seen as a kind of legislative corruption described in Jain (2001). In more extreme cases, $U_{C}$ may be seen as a direct payment received by compliant citizens, as in the case of vote buying in some countries where electoral frauds sometimes occur (see Carreras and repo glu 2013). It may also be interpreted in a latu sensu as a subjective utility gain of citizens with governmental corruption, for instance by false propaganda efforts of the government. These pay-offs are implicit when a citizen is compliant with corruption. ${ }^{4}$ These individual profits are far from being favorable to the development of social welfare, and moreover, they are antagonistic to the social interest.

Remark 2. Different groups or individuals typically receive different personal profits from a corrupt government. Given this disparity, the amount $U_{C}$ can be regarded as the average of benefits in a country, or in other words the benefit of a representative compliant citizen when a corrupt government is in charge. A similar interpretation holds for other quantities so that we can see them as typical average values.

The -1 term in the payoff of a compliant citizen corresponds to a payment of a bribe to a corrupt official or a dis-utility provoked in the citizens by an official's corrupt act. There is an extra dis-utility $U_{O}$ of a non-compliant citizen when meeting a corrupt official. The interpretation of this situation is twofold: a non-compliant citizen also gets a dis-utility $U_{O}>0$ in addition to the -1 forced payment because of his/her noncompliance or; a non-compliant citizen might decide not to pay the official in which case the utility or work due to money and time involved in all the process to solve the issue or service he/she requires will be more costly (by an amount $U_{O}$ ) than paying the official at once. The parameter $U_{O}$ may be regarded as an attrition that causes a utility loss

\footnotetext{
${ }^{4}$ For instance it is well documented that in some countries some distribution of benefits and/or payments by some politicians occurs for instance in the context of electoral campaigns (see Brusco, Nazareno, and Stokes (2004)). In these cases it is often reported that even if people acknowledge these as corrupt practices, they do not explicitly condemn them, and indeed accept such payments, therefore acting in a compliant way. Another example would be using fake news to denigrate the image of the political opposition and, by comparison, to make the government appear as less corrupt which may have an effect on citizens.
} 
because of the contact of a citizen that is not compliant toward corruption with a corrupt official.

\subsection{The officials}

We will consider officials appointed by a central authority (the government) to provide certain services required by citizens, or necessary to the administration of the state. Their functions will be to carry out the administrative tasks that citizens require daily such as building permits, exploitation of natural resources, control of compliance with laws, control of tax payments, various kinds of management.

These officials can perform a given duty honestly or dishonestly, which we will proverbially call non-corrupt and corrupt, respectively. In the former case the official acts respecting the objectives of his/her functions in accordance with the law. Dishonesty may have very different forms. A dishonest action (which we will call a corrupt action) occurs when the official uses his/her investiture to seek direct personal benefit different from that implied by his/ her functions, or it may take the form of an indirect benefit for himself/herself from a third party (e.g. family member, an acquaintance, a company). In the case of this model we use a simplified version summarizing all these nuances. We evaluate this in a monetary unit +1 .

The payoffs of the officials are given in the following table (Table 2).

- $F$ is the fine imposed by an honest government to a corrupt official.

- $P_{O}$ is the utility transferred (payments, bribes, fines) from the corrupt officials to the corrupt government to keep their corrupt behavior unpunished.

- $P_{\bar{O}}$ is the utility transferred (payments, bribes, fines) from the non-corrupt officials to the corrupt government to keep their jobs or because of political alignment.

Fines and punishments by the government are average values observed in society representing the average/typical pay-offs for the officials in a society.

\subsection{The government}

We will consider a central authority or government which has responsibility and influence in corruption phenomena in a society. Indeed, the government may be seen as a guardian against corruption at other levels but that may itself be corrupted. However, there are expected effects of voting that are

Table 2. The pay-off table of the officials in the threepopulation game.

\begin{tabular}{lllll}
\hline & $G, C$ & $G, \bar{C}$ & $\bar{G}, C$ & $\bar{G}, \bar{C}$ \\
0 & $1-P_{O}$ & $1-P_{O}$ & $1-F$ & $1-F$ \\
$\bar{O}$ & $-P_{\bar{O}}$ & $-P_{\bar{o}}$ & 0 & 0 \\
\hline
\end{tabular}


characteristic of democracy that influence the actions of the government. Government non-corruption perceived by citizens is in general an incentive to vote for the reelection of the government or the political party that supports it. This incentive is even more important for those citizens who prefer to follow the legally established norms. On the other hand, perception of government corruption can be blurred by lack of information or false news reaching the citizens.

The pay-off table for the government is as follows (Table 3).

- $V_{C, G}$ is the voting valuation attributed by a corrupt government for reelection by compliant citizens.

- $V_{\bar{C}, G}$ is the voting valuation attributed by a corrupt government for reelection by non-compliant citizens.

- $V_{C, \bar{G}}$ is the voting valuation attributed by a non-corrupt government for reelection by compliant citizens.

- $V_{\bar{C}, \bar{G}}$ is the voting valuation attributed by a non-corrupt government for reelection by non-compliant citizens.

These voting valuations represent the estimated influence (in utility terms) of governmental corruption in the citizens' vote in favor of reelection of a government. In other words, they reflect the expected values that a government assigns to be maintained in power for one period more according to the vote of the citizens in an election. In other words it is an assessment by the government of its actions/behaviors in the public space regarding relations to the citizens in terms of the expected effects of voting. From the point of view of citizens these reflect their voting power.

Recalling Remark 1, we consider the quantities $V_{C}$ and $V_{\bar{C}}$ given by

$$
V_{C} \equiv \Delta V_{C}=V_{C, \bar{G}}-V_{C, G} \text { and } V_{\bar{C}} \equiv \Delta V_{\bar{C}}=V_{\bar{C}, \bar{G}}-V_{\bar{C}, G} \text {. }
$$

In the subsequent analysis, the voting valuations $V_{C}$ and $V_{\bar{C}}$ will be of vital importance.

For instance, in a well-functioning democracy, the value $V_{C}$ can be large when compliant citizens are concerned with perceived high levels of corruption because they have to deal with it in their daily life and they might prefer to live according to the established legal norms. In this case we may say that citizens have high voting power. Furthermore, the value $V_{\bar{C}}$ can be smaller than $V_{C}$ because non-compliant citizens may be less aware of government corruption. In an ill-functioning democracy, the value $V_{C}$ can be small (or negative) when compliant citizens do not have credible alternatives to

Table 3. The pay-off table of the government in the three-population game.

\begin{tabular}{lllll}
\hline & $O, C$ & $O, \bar{C}$ & $\bar{O}, C$ & $\bar{O}, \bar{C}$ \\
$G$ & $P_{O}-L$ & $P_{O}$ & $P_{\bar{O}}-L$ & $P_{\bar{O}}$ \\
$\bar{G}$ & $V_{C}+F-J$ & $V_{\bar{C}}+F-J$ & $V_{C}$ & $V_{\bar{C}}$ \\
\hline
\end{tabular}


a corrupt ruling elite and they see corruption as a usual circumstance with which they have to live, and even more, they would prefer to violate the law since it is the usual stance in such a state of affairs.

If both values $V_{C}$ and $V_{\bar{C}}$ are high enough then the citizens in a democratic state are able to fight government corruption successfully. However, if the non-compliant citizens are not aware of corruption then $V_{\bar{C}}$ might be small (or negative), allowing the government to change its practices gradually from noncorrupt to corrupt acts. If corruption is high but there is a large number of compliant citizens (and so aware of the high levels of corruption) that want to use the voting power to fight corruption, then $V_{C}$ might be large enough to impose significant internal changes in the government to become less corrupt or even to overturn the corrupt government. Conversely, if vote-buying practices used by a corrupted government are successful and democracy is undermined, then $V_{C}$ can be negative creating a self-reinforcing mechanism between the compliant citizens and the corrupted government (as in Victor Hugo's aforementioned quote).

- $J$ is a cost related to the maintenance of the judiciary system and other anti-corruption mechanisms by a non-corrupt government to fight corruption.

- $L$ is a loss that a corrupt government incurs to influence and increase its chances of remaining in power by keeping the status quo of corruption. It may be seen as a cost or a payment by the government to provide fiscal benefits to some sectors of the population, to buy votes or the costs of propaganda efforts.

It is often observed that whenever a corrupt ruler elite has a short time horizon it may in some way appropriate property or abrogate previously signed contracts and generally ignore the long-run economic consequences of their choices and focus on short-term decisions (see for instance Olson (1993)). A corrupt elite with such a short time horizon may thus take welfare even from those who could act as accomplices, in our case the officials. This is measured by $P_{O}$ and $P_{\bar{O}}$ and represents the relations and network of corruption of a government toward its bureaucracy and lower level elite. When the government is non-corrupt but corruption exists at the level of the officials, the quantities $F, P_{O}$ and $J$ interplay. They may be seen respectively as a benefit and costs of the government's action against corruption and will be important in the evolutionary outcomes as we shall see. More precisely, the quantity $F-$ $J-P_{O}$ is a measure of non-corrupt government's efficiency in fighting corruption. This is related to the quality and effectiveness of the justice system of a non-corrupt government.

\section{The evolutionary dynamics of corruption in a society}

In this section, taking into account the individual behaviors of the different protagonists, who in a given society face the dilemma of corruption, we build 
an evolutionary dynamical system model based on the replicator dynamics. A state of the system, in general terms, measures the distribution of corruption among society, like the frequency of corrupt acts carried out by individuals or institutions. The parameters of the game modeling the conflict, in general terms, describe some socio-political and economical characteristics of a society. Once an initial condition is given and the values of the parameters are fixed, the evolutionary trajectories of corruption in such society are determined by the model. Future evolution will be modified if the initial condition or the values of these parameters are changed. Based on this observation, it is possible to dynamically interpret the effects of such initial conditions and parameters on corruption evolution. Hence, the model gives an insight into the mechanisms at work and how to define policies and lines of action which may contribute to combat or prevent the growth of corruption.

We will characterize the evolution of corruption in a society by a system of three differential equations, each one corresponding to the dynamical behavior of the strategy or distribution among the two types for each one of the three populations of the game. The trajectories of this system represent the possible evolution of corruption in the society in the three levels corresponding to each one of the players or populations of the game. Taking into account the classification of various types of corruption presented in Jain (2001), we have that our dynamical system tracks the evolution of grand corruption at the level of the political elites, such as the government, the dynamics of petty corruption that occurs at the level of officials, and finally the dynamics of citizen's compliance to corruption. The insight of evolutionary game theory is that selection will act to evolutionarily choose the options which will locally increase the utilities of the agents in the population. Replicator dynamics assumes that players in the populations compare the expected utilities from the use of each one of the pure strategies and will increase the proportions of the pure strategies that will perform better. Following Weibull (1995), the replicator dynamics turns into the following set of ordinary differential equations:

$$
\left\{\begin{array}{l}
\dot{g}=g(1-g)(E(G)-E(\bar{G})) \\
\dot{o}=o(1-o)(E(O)-E(\bar{O})) \\
\dot{c}=c(1-c)(E(C)-E(\bar{C}))
\end{array}\right.
$$

We use the notation $E(\cdot)$ for the expected value of a pure strategy of a player/ population given the distribution or mixed strategy of the other players/ populations. After some algebra we have that these equations may be written in the form:

$$
\left\{\begin{array}{l}
\dot{g}=g(1-g)\left(E_{g} o+B_{g} c+D_{g}\right) \\
\dot{o}=o(1-o)\left(A_{o} g+D_{o}\right) \\
\dot{c}=c(1-c)\left(A_{c} g+U_{O} o-U_{\bar{G}}\right)
\end{array}\right.
$$


where

$$
\begin{aligned}
& E_{g}=J+P_{O}-F-P_{\bar{O}} \\
& B_{g}=V_{\bar{C}}-V_{C}-L \\
& D_{g}=P_{\bar{O}}-V_{\bar{C}} \\
& A_{o}=F+P_{\bar{O}}-P_{O} \\
& D_{o}=1-F \\
& A_{c}=U_{C}+U_{\bar{G}}-U_{G}
\end{aligned}
$$

Once the parameters of the model are fixed, then the dynamical system is well defined and if in addition the initial conditions are given the system has a unique solution. Thus the trajectories of the dynamical system will reflect the possible evolution paths of corruption in the society according to our model. Societies with similar or even equal initial conditions can evolve to very different steady states according to the parameters which reflect the characteristics of the society. This means that changes in public policies or other events with repercussions in the values of the parameters of the model can give place to changes in the trajectories of corruption. We will characterize the role of these parameters and its relevance in the fight against corruption or in the perpetuation of corruption.

The relevant state space for the dynamics is the unit cube $\mathcal{C}=[0,1]^{3}$. The vertices are the states where each agent/population has only individuals of one type, i.e. all agents following the same pure strategy/behavior. The edges are the states where agents/population have only individuals of one type, except for one agent/population that can opt by a mixed strategy, or alternatively has individuals of different types. The dynamics close to the vertices and edges are crucial to help to understand the global dynamics. We observe that each vertex is a fixed point or equilibria for the dynamics, and each edge and face of the unit cube are invariant for the dynamics. As usual, the stability of the equilibria of the dynamical system (1) will be essential in our analysis.

Each edge of the unit cube has two fixed coordinates and one free coordinate. The dynamics along an edge is obtained by looking at the relevant equation of the dynamical system (2), i.e. the equation of the free coordinate and substituting the values of the fixed coordinates. A special feature of the replicator dynamics is that this value is constant along each edge. After substitution, the value of the free coordinate will increase if the obtained quantity is positive and it will decrease if the quantity is negative. If it is zero, we are in a degenerate case where all the points at the edge are dynamical equilibria. The quantities characterizing the vector field along the edges of the unit cube are related to the model parameters and have social, economical and political interpretations that we will use in the analysis in the following sections and play a very important role in the overall dynamics. In Figure 1 we depict the behavior of the dynamics along the edges of the unit cube. Each 


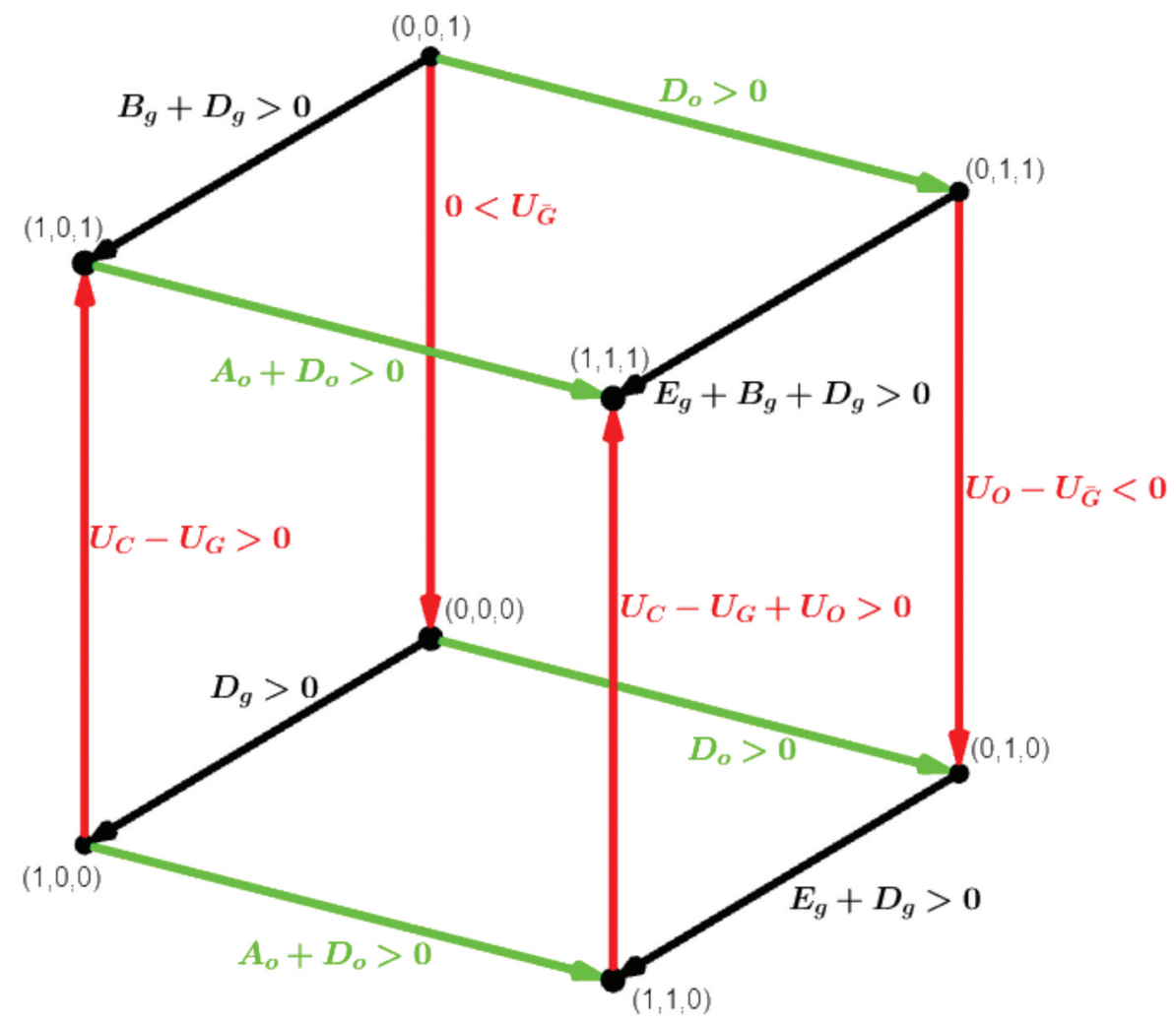

Figure 1. The dynamics and relevant quantities on the edges of the unit cube with each player/ population in different colors: black for the government, green for the officials and red for the citizens.

player/population of the game is represented by a different color. We also present the relevant quantities determining the dynamics on each edge.

\subsection{The interior mixed equilibrium}

Apart from studying the stability of the equilibria that are at the vertices, it is useful to study the interior mixed equilibrium. By some simple algebra, we find that the interior mixed equilibrium $Q^{*}=\left(g^{*}, o^{*}, c^{*}\right)$ is given by:

$$
\begin{aligned}
g^{*} & =-\frac{D_{o}}{A_{o}} \\
o^{*} & =\frac{A_{o} U_{\bar{G}}+A_{c} D_{o}}{A_{o} U_{O}} \\
c^{*} & =-\frac{A_{o}\left(D_{g} U_{O}+E_{g} U_{\bar{G}}\right)+A_{c} E_{g} D_{o}}{A_{o} B_{g} U_{O}}
\end{aligned}
$$


We observe that if the parameters of the model are such that the inequalities $0<g^{*}, o^{*}, c^{*}<1$ hold then $Q^{*}$ is a mixed steady state for the dynamical system in the interior of the unit cube and, so, it is a Nash equilibrium for the game (see Weibull (1995) for the details). This stationary state is characterized by the fact that government, officials and citizens are indifferent between their pure actions, i.e.

$$
E(G)=E(\bar{G}), E(O)=E(\bar{O}) \text { and } E(C)=E(\bar{C}) .
$$

To study the stability of the mixed equilibria we will make use of the following notation:

$$
G^{*}=g^{*}\left(1-g^{*}\right), O^{*}=o^{*}\left(1-o^{*}\right), C^{*}=c^{*}\left(1-c^{*}\right) .
$$

When $G^{*} O^{*} C^{*}=0$ then at least one of these is zero which means that the mixed equilibrium is on the boundary of the cube, which may be a face, an edge, or a vertex. The Jacobian matrix of the linearization at the mixed equilibrium is

$$
\left[\begin{array}{ccc}
0 & G^{*} E_{g} & G^{*} B_{g} \\
O^{*} A_{o} & 0 & 0 \\
C^{*} A_{c} & C^{*} U_{O} & 0
\end{array}\right]
$$

whose eigenvalues are the roots of the characteristic polynomial:

$$
\lambda^{3}-\lambda\left(G^{*} O^{*} E_{g} A_{o}+G^{*} C^{*} B_{g} A_{c}\right)-G^{*} O^{*} C^{*} B_{g} A_{o} U_{O} .
$$

Since it is a cubic polynomial, there is a real root. Vieta's formulas imply that the sum of the three roots of the above polynomial is zero. There are two cases:

1. $B_{g} A_{o} U_{O}=0$. Then one of the roots is zero. The other two are either two conjugate pure imaginary numbers, or two symmetric real numbers. In this case the point is not hyperbolic and Hartman-Grobman's is not applicable.

2. $B_{g} A_{o} U_{O} \neq 0$. Then zero is not a root. Hence the polynomial has a non-zero real solution and so must have another solution with non-zero real part of opposite sign. Hartman-Grobman's theorem implies that the mixed equilibrium is a saddle.

When $B_{g} A_{o} U_{O}=0$ we are again in a degenerate case in which either $A_{o}=0$ or $B_{g}=0$ (since we assumed $U_{O}>0$ ). It can be readily seen from the expressions (3) defining the mixed equilibrium that when $A_{o}=0$ or $B_{g}=0$ the mixed interior equilibrium is not defined. So we conclude that when the completely mixed equilibrium exists, i.e. it is in the interior of the unit cube, then it is always a saddle, and it may be a spiraling saddle when there are roots with non-zero imaginary part.

We cite some useful facts about the replicator dynamics whose proofs may be found in Weibull (1995). First, in the long run dominated pure strategies are not used. Most importantly, asymptotically stable states correspond 
precisely to strict Nash equilibria. This implies that a mixed equilibrium is never asymptotically stable. So only the vertices of the cube can be asymptotically stable. Furthermore, the study of the stability of the vertices can be made by analyzing the behavior of the dynamics along its incident edges. We will show that the dynamics along the edges have very useful social, economical and political interpretations in terms of the parameters of the model.

\section{Bi-stability: full-corruption vs. no-corruption}

In this section we study a scenario where a bi-stable situation occurs, i.e. the coexistence of two stable equilibria, where nonetheless, one of them is socially preferable to the other: the no corruption equilibrium and the full corruption equilibrium are asymptotically stable.

Firstly, we focus our attention on the stability of the no-corruption scenario $(0,0,0)$, i.e. the equilibrium where both government and officials are noncorrupt and citizens are non-compliant accordingly. The equilibrium $(0,0,0)$ is asymptotically stable if and only if $D_{g}<0, D_{o}<0$ and $U_{\bar{G}}>0$ (see Weibull (1995)). These inequalities are equivalent to the vector field in the three edges that are incident to the vertex $(0,0,0)$ to point toward the vertex $(0,0,0)$. Hence, in a neighborhood of the vertex $(0,0,0)$, we have

$$
\left\{\begin{array}{l}
\dot{g}=g(1-g)\left(E_{g} o+B_{g} c+D_{g}\right)<0 \\
\dot{o}=o(1-o)\left(A_{o} g+D_{o}\right)<0 \\
\dot{c}=c(1-c)\left(A_{c} g+U_{O} o-U_{\bar{G}}\right)<0
\end{array}\right.
$$

We now analyze the social, economical and political implications of the asymptotic stability of the no-corruption scenario $(0,0,0)$. The government is non-corrupt when citizens' compliance is low, officials corruption is low and $P_{\bar{O}}<V_{\bar{C}}$ (equivalently $D_{g}<0$ ), i.e.

$$
\dot{g}=g(1-g)\left(E_{g} o+B_{g} c+D_{g}\right)<0 .
$$

This occurs when the voting valuation by the government from the noncompliant citizens is higher than the possible gains from corrupt actions of the government. The utility $P_{\bar{O}}$ to be low can also be interpreted as the judiciary system to be working well, not allowing a corrupt government to take gains from corrupted actions of officials and institutions. This promotes a fair relationship between the government and its bureaucracy. The officials are non-corrupt when government corruption is low and $F>1$ (equivalently $\left.D_{o}>0\right)$, i.e.

$$
\dot{o}=o(1-o)\left(A_{o} g+D_{o}\right)<0 .
$$

This means that the fines imposed by the non-corrupt government, which is a cost for the officials, is higher than the benefits from corrupt practices by the 
officials. The citizens are not compliant when officials' corruption is low, government corruption is low and $U_{\bar{G}}>0$, i.e.

$$
\dot{c}=c(1-c)\left(A_{c} g+U_{O} o-U_{\bar{G}}\right)<0 .
$$

The utility of the citizens $U_{\bar{G}}$ is positive when the institutions and the judiciary system work well and protect the citizens.

Secondly, we focus our attention on the stability of the full corruption scenario $(1,1,1)$, i.e. the equilibrium where both government and officials are non-corrupt and citizens are non-compliant accordingly. The equilibrium $(1,1,1)$ is asymptotically stable if and only if $E_{g}+B_{g}+D_{g}>0, A_{o}+D_{o}>0$ and $A_{c}+U_{O}-U_{\bar{G}}>0$ (see Weibull (1995)). These inequalities are equivalent to the vector field in the three incident edges to the vertex $(1,1,1)$ pointing toward the vertex $(1,1,1)$. Hence, in a neighborhood of the vertex $(1,1,1)$ we have

$$
\left\{\begin{array}{l}
\dot{g}=g(1-g)\left(E_{g} o+B_{g} c+D_{g}\right)>0 \\
\dot{o}=o(1-o)\left(A_{o} g+D_{o}\right)>0 \\
\dot{c}=c(1-c)\left(A_{c} g+U_{O} o-U_{\bar{G}}\right)>0
\end{array}\right.
$$

Now we analyze the economic social and political implications of the asymptotic stability of the no-corruption scenario $(1,1,1)$. The government is corrupt when citizen compliance is high, officials corruption is high and $P_{O}+$ $J>V_{C}+F+L$ (equivalently, $E_{g}+B_{g}+D_{g}>0$ ), i.e.

$$
\dot{g}=g(1-g)\left(E_{g} o+B_{g} c+D_{g}\right)>0
$$

This means that the gains with the corrupt actions of the government overcome the fines applied to the corrupt officials even with the associated costs as vote buying and practices of clientelism. Observe that in this case the democracy is undermined, or we might be in an extreme case of a dictatorship or authoritarian regime (see Accinelli et al. (2017)), because compliant citizens are not able to fight corruption using the power of the vote $\left(V_{C}\right.$ is not large enough to fight corruption). The officials are corrupt when the government corruption is high and $1-P_{O}>-P_{\bar{O}}$ (equivalently $A_{o}+D_{o}>0$ ), i.e.

$$
\dot{o}=o(1-o)\left(A_{o} g+D_{o}\right)>0 .
$$

This means that the gains of the officials with corrupt acts are large enough to compensate for utility transferred to the corrupt government. The citizens are compliant when the government corruption is high, officials corruption is high and $U_{C}>U_{G}-U_{O}$ (equivalently $A_{c}+U_{O}-U_{\bar{G}}>0$ ), i.e.

$$
\dot{c}=c(1-c)\left(A_{c} g+U_{O} o-U_{\bar{G}}\right)>0 .
$$

This means that the utility transferred from a corrupt government to the compliant citizens is higher than the extra utility obtained by the non- 
compliant citizens. This can be the case of vote buying or when the judiciary system does not work well, and the social beliefs of citizens against corruption are low.

The bi-stability scenario occurs when the no-corruption equilibrium and the full-corruption equilibrium are asymptotically stable, i.e. the above six inequalities hold simultaneously. The intuition is that there are two selfreinforcing mechanisms occurring simultaneously, one for the nocorruption equilibrium and other for the full corruption equilibrium. We observe that in this case the initial condition of the society determines to which equilibrium the society evolves. This situation is akin to a social trap since there are two stable equilibria, which are also Nash equilibria for the original game, one of which is Pareto dominated and another one, socially preferable in the Pareto sense with low levels of corruption (for more on social traps see Rothstein (2005)).

We plot some trajectories for this bi-stability scenario in Figure 2. The interior mixed equilibrium is very relevant for the dynamical outcome. In this situation the interior mixed equilibrium has a positive real eigenvalue and a pair of complex conjugate eigenvalues with negative real part. Hence it has a stable manifold with dimension two, whose boundary is an unstable heteroclinic cycle, and an unstable manifold of dimension one. The stable manifold intercepts the cube in a heteroclinic cycle which is a repelling since trajectories follow the stable manifold in a spiraling way due to a pair of complex eigenvalues approaching the interior mixed equilibrium, and subsequently, the trajectories follow the transverse direction influenced by the unstable one-

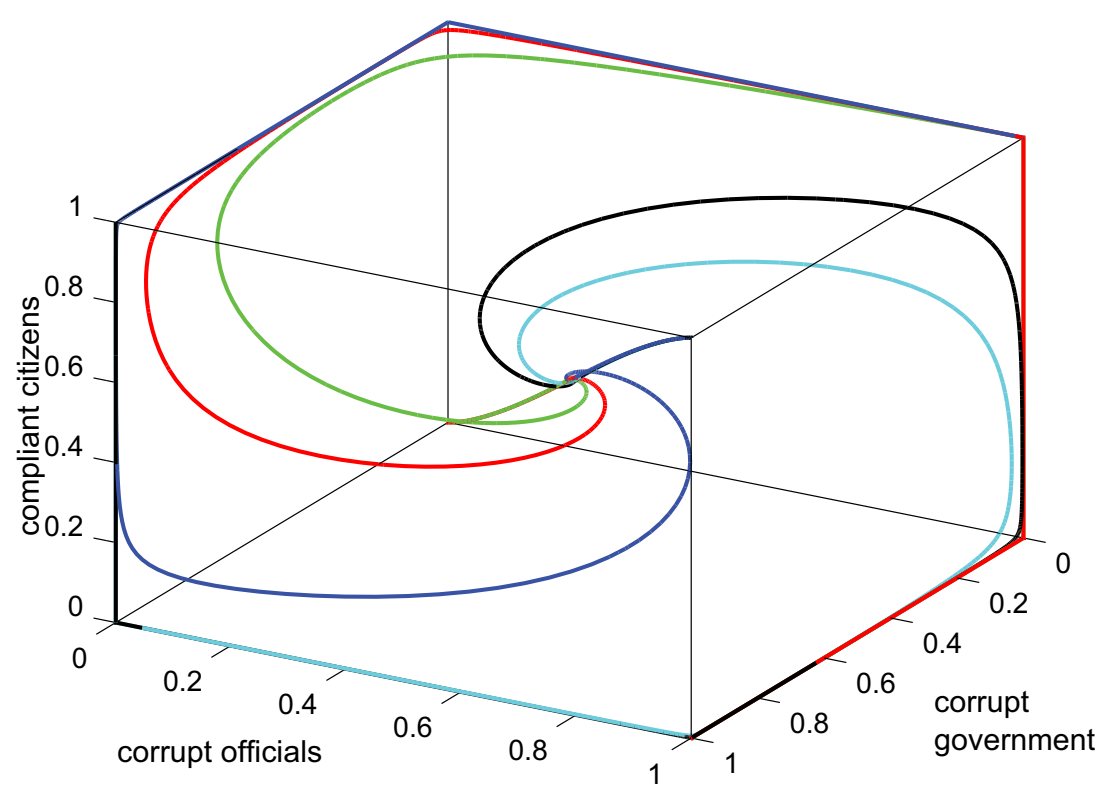

Figure 2. A repelling heteroclinic cycle leading to a bi-stable scenario. 
dimensional manifold of the interior mixed equilibrium, whose boundary consists of the two asymptotically stable equilibria. In this case there is a twodimensional manifold separating the interior of the unit cube into two parts, which are the basins of attraction of the two stable equilibrium points. Hence, evolution is initial condition dependent and changes in the initial condition will give place to important changes in the future evolution of corruption: in one side of the stable manifold society is evolving to a corruption social trap and, on the other hand, an equilibrium of low levels of corruption.

\section{Corruption cycles}

In this section we show the appearance of stable heteroclinic cycles of corruption. Furthermore, we show that two heteroclinic cycles coexist for a given set of parameters such that for a subset of these parameters one is stable and for the other subset of these parameters the other is stable.

The heteroclinic cycles are determined by six-letter words, like GOCG $\bar{O} \bar{C}$, where the order means the time sequence of the events and each letter means what will happen along time to that group in the edge under consideration of the cube. Similarly to the previous section, the behavior of the group along an edge is determined by the corresponding inequality. Hence, each heteroclinic cycle is determined by six inequalities that determine the space of parameters, where the heteroclinic cycle exists (albeit not necessarily stable).

The heteroclinic cycle GOCG $\bar{O} \bar{C}$ exists if and only if the following six inequalities hold. The government gets corrupt when citizen compliance is low and officials corruption is low when $P_{\bar{O}}>V_{\bar{C}}$ (equivalently $D_{g}>0$ ), i.e.

$$
\dot{g}=g(1-g)\left(E_{g} o+B_{g} c+D_{g}\right)>0 .
$$

The gains with the corrupt actions of the government are higher than the voting valuation by the government from the non-compliant citizens. It may be interpreted as that non-compliant citizens still do not have perceived the government corruption and so do not oppose, or that citizens are not sufficiently aware of corruption. The officials get corrupt when government corruption is high and citizen compliance is low when $1+P_{\bar{O}}>P_{O}$ (equivalently $A_{o}+D_{o}>0$ ), i.e.

$$
\dot{o}=o(1-o)\left(A_{o} g+D_{o}\right)>0 .
$$

The gains of the officials with the corrupt acts are large enough to compensate for utility transferred to the corrupt government. The citizens become compliant when government corruption is high and officials corruption is high when $U_{C}+U_{O}>U_{G}$ (equivalently $A_{c}+U_{O}-U_{\bar{G}}>0$ ), i.e.

$$
\dot{c}=c(1-c)\left(A_{c} g+U_{O} o-U_{\bar{G}}\right)>0 .
$$


The utility transferred from a corrupt government to the compliant citizens is higher than the utility obtained by non-compliant citizens. Furthermore, the dis-utility of non-compliant citizens due to the corrupt officials is high. For instance, when the judiciary system is weak and the institutions do not work properly, if the citizens do not pay the bribes asked, they might have to face a very costly process or put themselves in danger. The government corruption gets low when citizen compliance is high and officials corruption is high when $P_{O}+J<V_{C}+F+L$ (equivalently $E_{g}+B_{g}+D_{g}<0$ ), i.e.

$$
\dot{g}=g(1-g)\left(E_{g} o+B_{g} c+D_{g}\right)<0 \text {. }
$$

Hence, the voting valuation $V_{C}$ by the government from the compliant citizens is high enough to force the government to become non-corrupt or the citizens elect a new government that is less corrupt. The officials get less corrupt when government corruption is low and citizen compliance is high when $F>1$ (equivalently $D_{o}<0$ ), i.e.

$$
\dot{o}=o(1-o)\left(A_{o} g+D_{o}\right)<0 .
$$

The fines imposed by the non-corrupt government are higher than the benefits from the corrupt practices of the officials. The citizens become non-compliant when government and officials corruption is low when $-U_{\bar{G}}<0$, i.e.

$$
\dot{c}=c(1-c)\left(A_{c} g+U_{O} o-U_{\bar{G}}\right)<0 .
$$

The utility of the citizens $U_{\bar{G}}$ when the institutions and the judiciary system work well and protect the citizens is positive.

We plot some trajectories for this scenario in Figure 3. In this scenario, there is a heteroclinic cycle connecting vertices of the unit cube and the connections are the edges of the cube. This cycle is attracting, because any trajectory beginning in the interior of the unit cube approaches it with the exception of the mixed steady-state which is an equilibrium of the system. The interior mixed equilibrium is relevant for the dynamical outcome and the appearance of the heteroclinic cycle. Indeed, the equilibrium has a negative real eigenvalue and a pair of complex conjugate eigenvalues with positive real part. Hence, it has a dimension two (i.e. a surface) unstable manifold and a transverse stable manifold with dimension one. The dimension two unstable manifold is topologically like a disk containing the interior mixed equilibrium inside the unit cube. The heteroclinic cycle is the boundary of such dimension two unstable manifold with the unit cube whose intersection produces the aforementioned cycle. So trajectories initially approach the interior mixed equilibrium and the unstable manifold following the stable manifold of the interior equilibrium and subsequently follow the unstable manifold going away from the equilibrium point. Thus they will approach the heteroclinic cycle in a spiraling way due to the pair of complex eigenvalues of the mixed 


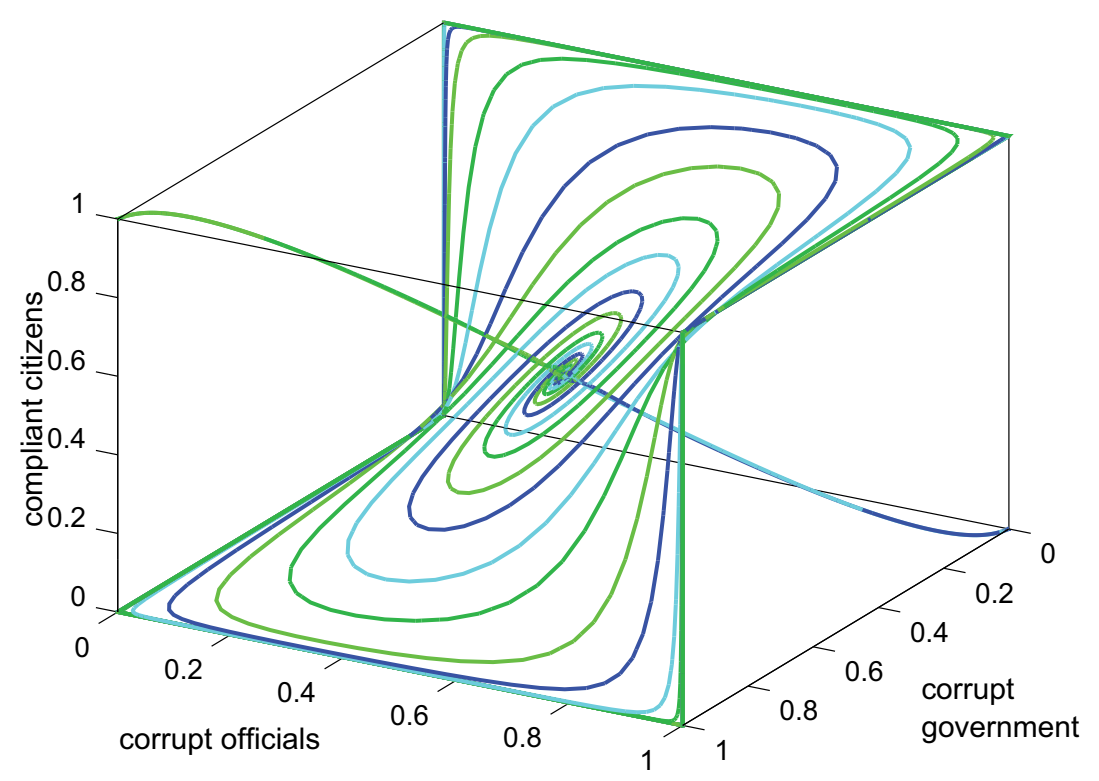

Figure 3. The GOC $\bar{G} \bar{O} \bar{C}$ attracting 6-edge heteroclinic cycle.

equilibrium. In Figure 3, we draw the one-dimensional stable manifold of the interior mixed equilibrium transverse to its two-dimensional unstable manifold.

We observe that heteroclinic cycles can co-exist. For instance the hetero-

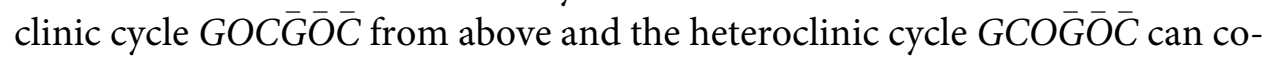
exist. In the heteroclinic cycle $G C O \bar{G} \bar{O} \bar{C}$, after the government becomes corrupt, the citizens become compliant and only after that the officials become corrupt. Hence, the heteroclinic cycle $G C O \bar{G} \bar{O} \bar{C}$ is determined by all the above inequalities, except the second inequality which is replaced by the following one:

$$
A_{c}-U_{\bar{G}}=U_{C}-U_{G}>0 .
$$

Hence, these two heteroclinic cycles co-exist, not necessarily being stable, when the seven inequalities discussed in this section hold. We observe numerically that for a subset of these parameters the heteroclinic cycle GOC $\bar{G} \bar{O} \bar{C}$ is stable (see Figure 3) and for other subset of these parameters the heteroclinic cycle $G C O \bar{G} \bar{O} \bar{C}$ is stable (see Figure 4 ).

\section{Conclusions}

It is well known that corruption is one of the major issues in today's political science and sociological studies. In democratic contexts, corruption can work as a mechanism which erodes democracy and citizenship and the legitimacy and trust of political systems. One major question is how does corruption 


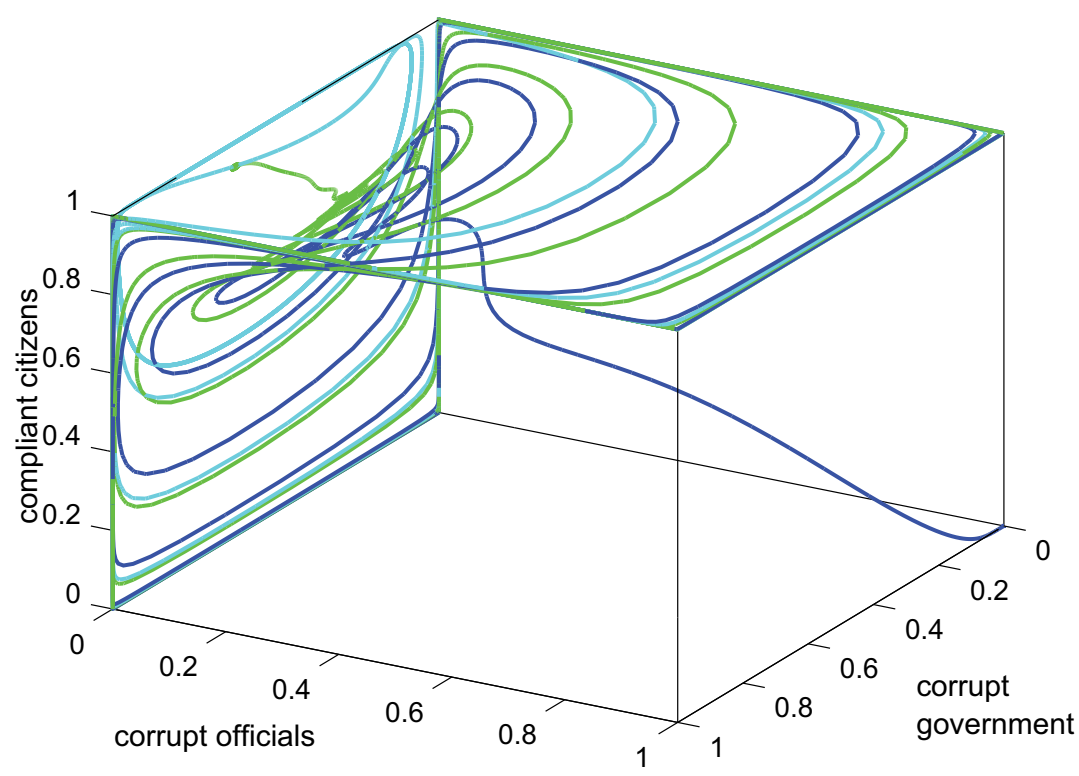

Figure 4. The $G C O \bar{G} \bar{O} \bar{C}$ attracting 6-edge heteroclinic cycle.

evolve and which mechanisms operate in its evolution and hence how is it possible to deter this process?

In this work we obtain some insight and heuristic to these questions by means of an evolutionary dynamical mathematical model of conflict between different socio/economical/political agents. We consider and analyze the effects of citizens in the evolution of corruption, who can be the victims of corruption even if benefiting from it, i.e. exhibiting some compliance to it. We considered an evolutionary model based on the replicator dynamics where the agents (considered as players of a multi-population normal-form game) compare their respective expected payoffs and update their behaviors/actions according to their average performances to attempt to improve their payoffs. The behaviors along time are evolutionarily selected by the replicator dynamics which appears as a natural mathematical tool to describe the evolution of corruption in a society, representing the spirit of evolution according to the strategies or behaviors that perform better in each circumstance. The dynamics allow us to analyze the possible paths of corruption involving the evolution of governmental corruption - grand corruption - the corruption of the officials - bureaucratic corruption - and the citizens' compliance toward corruption. The evolution of citizens' behavior/compliance toward corruption may have a large effect in the long-run evolution of corruption. The parameters of the model are interpreted in socio-political and economical terms, namely that of institutions that have an influence on the dynamics of the game, and also including parameters relative to citizens' relation to governmental and officials corruption. 
The leading role that citizens play in democracy is made particularly clear by the existence of stable heteroclinic limit cycles. It corresponds to a functioning democracy where corruption advances but only up to a certain moment, since eventually low corruption levels are obtained again. Citizens' exposure to high corruption levels can trigger, by the power of the vote, subsequent changes in the behavior of the government that becomes less corrupt or is overturned.

The stability of these cycles will depend on the values of the parameters, so estimates of these values may be of interest to provide guidelines for the implementation of public policies aimed at avoiding or at least counteracting the development of high levels of corruption. Although in the introduction we have considered examples from the empirical literature as sources of inspiration for this model, future work will consist of expanding the complexity of the model and analyzing the behavior of the solutions when the values of the model parameters are modified and contrasting them with real cases. There is an extensive literature that accounts for the evolution of corruption in different countries. We understand that our model adapts well to different scenarios and will be of great help in understanding and developing public policies aimed at combating corruption.

We also considered another scenario corresponding to a bi-stable scenario of two extreme cases: equilibria exempt from corruption and, at the other end, of those societies where corruption ends up dominating and that may be seen as configuring a certain kind of a social trap. These cases depend not only on the influence of citizenship and democracy on corruption, but also on the status quo of the institutional framework within society such as measures and its efficiency against corruption.

Taking into account the existence of transient moments of high corruption there are several related topics regarding corruption and its evolution that can be envisaged within the game theory framework and tools. These may include the study of stochastic effects or random shocks in variables of the models. They may be related for instance due to effects that exogenous variables may have in the perception of corruption in citizens, particularly meaningful in periods of high corruption in such heteroclinic cycles. Such effects may be the result of the media, public influence such as manifestations, aftermaths of an election and government change, and the important topic of the effects of fake news and mass media in the public perception of corruption.

\section{Acknowledgments}

The authors would like to thank an anonymous reviewer for the very useful suggestion which vastly improved the paper. The authors would like to thank Laura Gardini and Elisabetta Michetti for the fruitful discussions regarding this work. 
This work is partially financed by National Funds through the Portuguese funding agency, FCT - Fundação para a Ciência e a Tecnologia - within project: UID/EEA/50014/2019; the project "Dynamics, optimization and Modeling", with reference PTDC/MAT-NAN/6890/2014 and the project "Modeling, Dynamics and Games" - MDG - with the reference PTDC/MATAPL/31753/2017.

Elvio Accinelli wishes to thank the dean of the Faculty of Economic Sciences of the UASLP for the support provided for the academic stay at the Faculty of Sciences of the University of Porto, where much of this work was elaborated and also the Department of Mathematics of University of Porto for their hospitality. Part of this work was done during Filipe Martins $\mathrm{PhD}$ research, who thanks FCT for a PhD scholarship with reference PD/BD/105726/2014. Atefeh Afsar would like to thank the financial support of FCT through a PhD grant of the MAPPDMA program with reference $\mathrm{PD} / \mathrm{BD} / 142886 / 2018$.

\section{Funding}

This work is partially financed by National Funds through the Portuguese funding agency, FCT - Fundação para a Ciência e a Tecnologia - within project: UID/EEA/50014/2019; the project "Dynamics, optimization and modelling", with reference PTDC/MAT-NAN/6890/2014 and the project " Modelling, Dynamics and Games" - MDG - with the reference PTDC/MAT-APL/ $31753 / 2017$.

\section{References}

Accinelli, E., \& Carrera, E. (2012). Corruption driven by imitative behaviour. Economics Letters, 117(1), 84-87. doi:10.1016/j.econlet.2012.04.092

Accinelli, E., Martins, F., Oviedo, J., Pinto, A., \& Quintas, L. (2017). Who controls the controller? A dynamical model of corruption. The Journal of Mathematical Sociology, 41 (4), 220-247. doi:10.1080/0022250X.2017.1388235

Bicchieri, C., \& Duffy, J. (1997). Corruption cycles. Political Studies, 45(3), 477-495. doi:10.1111/1467-9248.00092

Boswell, N. Z., \& Rose-Ackerman, S. (1996). Corruption and democracy. Proceedings of the Annual Meeting (American Society of International Law), 90, 83-90. doi:10.1017/ S0272503700085827

Brusco, V., Nazareno, M., \& Stokes, S. C. (2004). Vote buying in Argentina. Latin American Research Review, 39(2), 66-88. doi:10.1353/lar.2004.0022

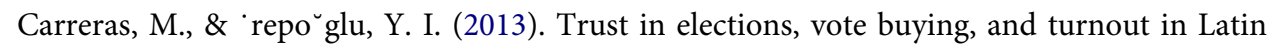
America. Electoral Studies, 32(4), 609-619. doi:10.1016/j.electstud.2013.07.012

European Union (EU). European anti-corruption report. Technical report, European Union, February 2014. https://ec.europa.eu/home-affairs/sites/homeaffairs/files/e-library/docu ments/policies/organized-crime-and-human-trafficking/corruption/docs/acr_2014_en.pdf.

Grego, J. (1886). A history of parliamentary elections and electioneering in the old days. Chatto and Windus. Re-edited by Nabu Press, November 2013. London : Chatto \& Windus Collection americana Digitizing sponsor Google Book from the collections of University of Michigan. https://archive.org/details/historyofparliam00greg

Gupta, S., Davoodi, H., \& Alonso-Terme, R. (2002). Does corruption affect income inequality and poverty? Economics and Governance, 3, 23-45. doi:10.1007/s101010100039

Hugo, V. (1864). William Shakespeare. A Lacroix, Verboeckhoven et Ciee, editeurs. Paris. https://fr.wikisource.org/wiki/William_Shakespeare_(Victor_Hugo) 
Jain, A. K. (2001). Corruption: A review. Journal of Economic Surveys, 15(1), 1-51. doi:10.1111/ 1467-6419.00133

Olson, M. (1993). Dictatorship, democracy, and development. The American Political Science Review, 87, 567-576. doi:10.2307/2938736

Rothstein, B. (2005). Social traps and the Problem of Trust. Cambridge University Press. doi:10.1017/CBO9780511490323

Seligson, M. (2002). The impact of corruption on regime legitimacy: A comparative study of four Latin American countries. Journal of Politics, 64, 408-433. doi:10.1111/14682508.00132

Sidorkin, O., \& Vorobyev, D. (2015). Political risk, information and corruption cycles: Evidence from Russian regions. SSRN Electronic Journal, 5. https://papers.ssrn.com/sol3/ papers.cfm?abstract_id=2606773

Soto, I. M., \& Cortez, W. (2015). The impact of political alternation on corruption in Mexico. Revista de Ciencia Política, 35(2), 371-392. doi:10.4067/S0718-090X2015000200006

Stokes, S. C. (2005). Perverse accountability: A formal model of machine politics with evidence from Argentina. American Political Science Review, 99(3), 315-325. doi:10.1017/ S0003055405051683

Stokes, S. C. (2009). Political clientelism. In C. Boix \& S. C. Stokes (Eds.), The oxford handbook of political science. Oxford University Press. doi:10.1093/oxfordhb/9780199566020.003.0025

Warren, M. E. (2004). What does corruption mean in a democracy? American Journal of Political Science, 48(2), 328-343. doi:10.2307/1519886

Weibull, W. J. (1995). Evolutionary Game Theory.MA: The MIT Press. 